\title{
The Conundrums of Counselling Women in Violent Intimate Partner Relationships in South Africa: Implications for Practice
}

\author{
Anne Fleischack $^{1}$ (D) $\cdot$ Catriona Macleod $^{1} \cdot$ Werner Böhmke $^{1}$ \\ Published online: 8 June 2019 \\ C) Springer Science+Business Media, LLC, part of Springer Nature 2019
}

\begin{abstract}
Little research focuses on how counsellors experience counselling encounters concerning intimate partner violence. This study reports on narrative research conducted with eight South African non-governmental organisation counsellors. Participants spoke of creating productive and caring counselling dynamics, and providing non-directive counselling. However, they also indicated providing moral guidance, particularly in cases where pregnancy or children were involved. Success was viewed rather narrowly as the women leaving the relationship, setting up 'all-or-nothing' outcomes. Such 'success' led to counsellor happiness, whilst failure in this regard led to counsellors experiencing anger and burn-out. We conclude that the conundrums evident in these data are grounded in patriarchal systems, limiting the efficacy of counselling based on a bondage and deliverance narrative. Implications for practice and training are also outlined.
\end{abstract}

Keywords Intimate partner violence · Counsellors · Narrative-discursive analysis · Narratives · Gendered power relations · South Africa

\section{Introduction}

Local and international research has shown that counselling for women who have experienced relationships characterised by intimate partner violence (IPV) can have many positive effects.

Anne Fleischack

annie.fleischack@gmail.com

Catriona Macleod

c.macleod@ru.ac.za

Werner Böhmke

w.r.bohmke@ru.ac.za

1 CSSR House, Department of Psychology, Rhodes University, Grahamstown, Kwazulu-Natal, South Africa 
These include women gaining confidence to leave a violent/abusive relationship (Hatcher et al. 2013; Jewkes et al. 2002; Rhodes and McKenzie 1998), considering options for solving problems within the relationship, and increasing their emotional wellbeing (Iverson et al. 2016; Rhodes and McKenzie 1998). Counselling, however, may also be challenging. For example, research into a Latino community in the USA revealed that counsellors sometimes did "not consider some potentially important personal barriers to reporting", such as the victim's shame (Lewis et al. 2005, p. 81).

Various models of conducting counselling in relation to IPV have been suggested in the literature. These include: viewing IPV relationships as developing in stages, and modelling therapy based on this perspective; a client-centred approach in which the counsellor facilitates the client in choosing solutions and actions that are compatible and appropriate for themselves (the client) (McHattie 2011); and a competency framework that focuses on counselling skills, specialist knowledge and specific personal characteristics needed for working with this client group (Roddy and Gabriel 2019). Research on the experiences of receiving counselling for IPV has been used to refine recommendations for the counselling encounter (Roddy 2016).

Little research has been conducted, however, on how counsellors themselves experience and describe their own positioning within the counselling encounter. Given the high level of gender-based violence in many countries (including South Africa, the site of this study), and that counsellors tend to be women, how the counsellors experience the counselling encounter in regard to IPV is an important aspect of understanding such counselling.

In this paper, we report on a study in which we interviewed counsellors, using narrative interviews, about their understandings of relationships characterised by IPV and how they, as counsellors, worked with IPV in their practice. All of the counsellors interviewed were women. We report, in this paper, on these counsellors' experiences of providing counselling within the context of the study.

\section{Background}

South Africa has one of the highest prevalence rates of IPV in the world (Britton 2006; Joyner and Mash 2011; Modiba et al. 2011, p. 872; Ntaganira et al. 2008). IPV cuts across all ethnic groups regardless of education or income level, or the victim's or perpetrator's line of employment (Modiba et al. 2011). South African research reveals that $19 \%$ of women have experienced a lifetime prevalence of domestic victimisation (Seedat et al. 2009) and 27.5\% of South African men reported abusing their current or most recent partner (Gupta et al. 2008).

There are many barriers that women face in South Africa when reporting IPV, related to resource constraints and social issues. The resource-related barriers include the relative lack of availability of healthcare or service provision facilities in the first place (Mbokota and Moodley 2004; Modiba et al. 2011; Njuho and Davids 2012). Other reasons include lack of adequate assistance due to problematic interactions with counsellors (Rasool Bassadien and Hochfeld 2005). That is, counsellors may sometimes view IPV as a private matter, or that it is a normal phenomenon, possibly leading to lack of action or non-interference (Rasool Bassadien and Hochfeld 2005); they may misdiagnose IPV (Joyner and Mash 2012), be afraid to intervene on behalf of the community (Lewis et al. 2005), and may not have received adequate or appropriate primary care training (noted locally, Mash et al. 2012, and globally, Watts and Mayhew 2004). In terms of social issues, some women may not report abuse due to conservative gender roles; e.g., the belief that the man is the head of the household and that 
his authority, and manner in which he runs the household, should not be questioned (Sugarman \& Frankel 1996, cited in Jewkes et al. 2002).

As a result of the relatively widespread acceptance of such conservative and traditional gender roles within South African society, IPV has, in many respects, become normalised within relationships. Women may either accept such violence as an everyday feature of their intimate relationships, or may see themselves as deserving of violent treatment from their partners for failing to adhere to culturally-located gendered expectations regarding their relationship roles (Kim and Motsei 2002; Wood et al. 2007). As a result, many women who experience IPV may feel that their violent partners were justified in their actions or that they did not harm them intentionally (Silverman et al. 2004). Women may also feel reluctant or ashamed about reporting IPV (Lewis et al. 2005) due to the personal, and sometimes sexual nature of the assault (Vogelman and Eagle 1991). Cultural and contextually mediated understandings of violence in intimate relationships, as well as subjective interpretations of the relative harm sustained, may also play a role. For example, anthropological research in South Africa has described violence in interpersonal relationships as being understood by those involved as a demonstration of love, depth of feeling, or emotional investment in the relationship, with women victims of IPV consequently downplaying the harm caused (Wood et al. 2008).

As noted earlier, IPV is also often not recognized by primary care providers and when it has been identified, the treatment has often been badly coordinated, fragmented, missed important aspects and/or lacked continuity (Joyner and Mash 2012). This may be due to the lack of appropriate or adequate training that healthcare workers receive, both globally (Watts and Mayhew 2004) and locally (Mash et al. 2012).

The South African non-governmental organisation (NGO) sector has played a role in addressing IPV. There are a number of safe houses available for abused women within South Africa (Kaldine 2007) often linked to NGOs. The South African NGO sector also has many organisations linked to women's movements, examples of which include Family Welfare Society and Living Hope. These NGOs offer various services including counselling for domestic violence, women's upliftment, empowerment programmes, interventions, legal support and shelter services. In essence, these organisations specifically aim to "engage masculinities within 'feminist' frameworks" due to "the growing institutionalisation and NGO-isation of the South African women's movement" (Britton 2006, p. 145).

\section{Counselling and IPV}

Due to the various problems surrounding access to counselling for IPV as noted above, effective help from counsellors and healthcare professionals is vital when IPV is reported. Indeed, "[a]chievement of an efficient healthcare system which enhances respect for women and children is likely to contribute to a reduction of violence in communities and [will] subsequently boost the quality of life in South Africa" (Njuho and Davids 2012, p. 280). Research shows that women who have utilised the services of counselling centres are able to consider options for solving problems within the relationship, increase their emotional wellbeing (Iverson et al. 2016; Rhodes and McKenzie 1998) and also develop an enhanced ability to physically remove themselves from the abuse (Hatcher et al. 2013; Jewkes et al. 2002).

A variety of models for conducting effective counselling for those experiencing IPV have been developed. For example, the care guidelines by Miller et al. (2002) outline 
addressing decision-making, which clinical services should be considered, and timelines for when intervention and assessment should occur. Feminist principles proposed by Mwau (2000) include helping women to explore options, acknowledging their strengths, assisting them with coping with shame or guilt, educating them about IPV dynamics and validating women's feelings.

Research conducted on clients' experiences of counselling has been used to enhance counselling dynamics. For example, women have emphasised the need to share their stories with counsellors within a safe and trustworthy environment (McHattie 2011; Roddy 2016) where there was sufficient time to explore issues (Roddy 2013). Other important factors are clients having their agency supported, being able to complete certain tasks, learning skills, having access to information, the importance of empowerment (McHattie 2011), and counsellors recognising diversity (e.g., same-sex partnerships) and nuances within relationships (Oswald et al. 2010). Overcoming shame in relation to IPV within a non-judgemental environment was also linked to feelings of acceptance and validation (Roddy 2013, 2016).

However, very little research has been conducted on the experiences of counsellors who work with IPV, with research of this kind being useful for enhancing the quality of counselling. Exceptions include Zust et al.'s (2017) study with evangelical pastors, who indicated that they were ill-prepared to deal with domestic violence, and that counselling focused mainly on keeping the children safe and helping victims/survivors to understand that the violence was not their fault. Iliffe and Steed (2000) found that counsellors in their study who were involved in IPV issues experienced vicarious trauma, reported changes in their views of safety and gender power issues, as well as feelings of isolation and powerlessness as a result of the involvement.

\section{Methods}

This study used a narrative-oriented inquiry (Hiles and Čermák 2008), based on the 'LightlyStructured Biographic-Narrative Interview Structure' by Wengraf (2001) - see further details below - to investigate the micro-narratives elicited from counsellors when they spoke about their understandings of IPV and their practice in relation to it. Narratives are "stories with words and meanings" that are linked to certain social groups and communities and provide information about the experiences and ways of life of these groups and communities (Jovchelovitch and Bauer 2000, p. 58). Micro-narratives can be defined as "short bursts of narrative interactionally embedded in question-answer sequences: several stories produced often in intricate relations to one another" (Blommaert 2006, p. 181). They often take the form of smaller, personal stories (Fok 2011) and are "provisional, contingent, temporary, and relative" (Barry 1995, cited in O’Donovan 2006, p. 475).

Although each person's narrative is idiosyncratic to their life experiences (Hiles and Čermák 2008), narratives also "enable human experiences to be seen as socially positioned and culturally grounded" (Hiles and Čermák 2008, p. 149; Young and Collin 2004). Thus it is suggested that people construct narratives by drawing upon culturally-available social and discursive resources.

Data were collected by means of interviewing counsellors, using Wengraf's (2001) method, who were based at two NGOs, one located in an urban and the other in a peri-urban area in the Eastern Cape, South Africa. These areas were chosen to ensure some diversity in the micronarratives. The clients who approach these NGOs are from a lower socio-economic bracket. The agencies offer a variety of services including individual, couple and family counselling, 
women's empowerment initiatives and working in conjunction with the magistrates' court and the police to process safe house referrals and protection orders, as well as handling divorce and maintenance orders. The counsellors also intermittently enter the local communities to share knowledge and information on human rights.

Across the two sites, eight counsellors were interviewed for this research; owing to the relative size of the organisations, two were recruited at the peri-urban site and six at the urban site. The participants all had experience counselling people who had experienced IPV. Seven of the counsellors were lay counsellors who had received in-house training and the other had a degree in Social Work. Some of the counsellors themselves had been abused by their partners and thus could be seen as 'wounded healers'. Counselling by 'wounded healers' may be beneficial as the counsellors are able to identify with the clients' traumatic experiences, and, through self-disclosure, can de-stigmatise the clients' experiences. On the negative side, however, counsellors may become too emotionally involved in their clients' situations, be unable to manage the countertransference set up in the encounter, and suffer from compassion fatigue (Zerubavel and Wright 2012).

At both sites, a client-centered, solution-based approach to counselling is adopted. After listening to the clients' stories, the counsellors, in a private, one-on-one setting, probe for more information, offer clients a variety of options for action, provide emotional support for the particular path chosen by the client, and offer to link the clients directly to places where they can get help.

The study was granted ethical clearance by the Rhodes University Psychology Department's Research Projects and Ethics Review Committee. Counsellors all provided their consent for the interviews to be conducted, including the fact that the interviews would be digitally recorded. The participants were assured that they would not be asked to divulge sensitive personal issues (e.g. their own histories in relation to IPV), as our research was focused on their experiences of their counselling. Locations and names mentioned in the interviews were kept non-specific and the participants were asked to choose pseudonyms so as to ensure that the information could not be linked back to them. All of the participants were women; seven were Black and spoke isiXhosa as a home language; one was White with English as a home language. All were fluent in English.

The first author and a co-researcher together conducted three separate interviews with each of the eight participants, using Wengraf's (2001) method. This interview method allows the content of the narratives to guide further questions that the interviewers might ask. During the interviews, the co-researcher took notes, specifically focusing on topics that emerged during the elicitation of counsellors' micro-narratives. In the first interview, the counsellors were asked, using an open-ended narrative-inducing question, to share their understandings of IPV, and their experiences with conducting counselling sessions with clients who were in relationships characterised by IPV. In the second interview, held 15 min after the first one, the researcher asked questions based on topics that had emerged during the first interview. The third and final session was conducted two months later, once the data had been transcribed and after a preliminary analysis had been conducted on the data, so as to determine which topics would be suitable for follow-up questions in the final interview.

The data were transcribed verbatim using Parker's (1992) transcription conventions (see Appendix). These conventions were selected as they provide details of the talk (pauses, interruptions, etc.) without being too technical. The data were analysed using aspects of Taylor and Littleton's (2006) narrative-discursive method in order to examine the micro-narratives that emerged during the interviews with the counsellors. Taylor and Littleton's (2006) approach focuses, inter alia, on how micro-narratives enable subject positioning (the depiction of people within particular roles and responsibilities) to take place. The interview recordings were 
listened to several times and the transcription read at the same time. The transcribed data were imported and coded using QSR NVIVO 10, a qualitative data analysis software program. Coding centred on the identification of micro-narratives. In the analysis, we examined common micro-narratives occurring across the interviews and at different times in the same interview, which allowed us to see patterns in the counsellors' micro-narratives. All three authors engaged with the analytical process, and the findings were presented to peers in order to refine the analysis.

\section{Findings}

The following micro-narratives were identified across the interviewees' data: 'we develop good counselling dynamics', 'we use non-directive counselling', 'when things go well, we feel positive', 'counselling IPV victims is emotional labour' and 'we provide moral guidance and suggestions'. With regard to each of these, the subject positions enabled by the micronarratives, and the implications for counselling are discussed below.

\section{We Develop Good Counselling Dynamics}

The counsellors shared that they utilised a variety of session management tools (praise for clients; listening deeply; building trust) in order to create a positive environment and appropriate counsellor-client session relationships/dynamics. In this way they positioned themselves as professional, and as following well-established counselling techniques.

Some of the counsellors indicated that they praised their clients for coming to see them. This, they explained, formed a positive relationship between the client and counsellor, as can be seen in the following extracts:

\section{Extract 1:}

Duvi (P5): ...so the woman straight away she's going to be straight and say that 'enough is enough $/ \mathrm{hmm} / \mathrm{ja}$ 'when I am looking at myself ... I see that I'm going nowhere' $/ \mathrm{hmm} / \mathrm{hmm}$...I even congratulate her $/ \mathrm{mmm} /$ saying that 'no-one forced you to come here' /mmm::/ meaning that you are ready to take any step.

\section{Extract 2:}

Lwando (P3): ....as for us at [name of NGO] (.) once a woman take[s] a step forward $=/ \mathrm{mmm} /$ (.) to look at herself $=/ \mathrm{mmm} /($.) we see that as a survivor person $=/ \mathrm{mmm} /=$ because once you find that $\ldots$ you need $i$-advice $=/$ yes $/=$ you need $i$-solution $/ \mathrm{mmm} /$ you need to find out what will work for you $/ \mathrm{mmm} /$ so once you take a step (.) we take you ... as a great survivor.

In the above extracts, Duvi spoke of attempting to build a positive relationship with her client by "congratulat[ing]" her for coming to see her, and Lwando by "see[ing] that [person] as a survivor". These affirmations are seen as important to the process of taking "steps" in the right direction; i.e., the women moving towards solving the problem. 
Across the dataset, interventions were viewed by the counsellors as something that should help the women leave their IPV situation. These extracts reveal how a story of bondage and then of deliverance (see Haaken 2010), or at least the possibility of deliverance ("you are ready to take any step"; "we take you as a great survivor"), provided a positive framing that counsellors encouraged in the session. The client's movement from victim to survivor through extracting herself from the relationship was viewed by the participants as an essential element of successful counselling.

Counsellors acknowledged that the movement from victim to survivor requires counselling labour. Some of the counsellors mentioned providing a space to listen empathetically and attentively to their clients as an important counselling management tool, seen in the extracts below.

\section{Extract 3:}

Lwando (P3): ...it's ... the matter of (.) putting yourself (.) in her shoes... you listen and then you understand (.) what actually is happening ... your intervention will be based (.) on the things that (.) come up ... listening it's a very important because your response (.) will depend (to) [on] the story $=/$ yes $/$ =because the stories are very different.

Extract 4:

Duvi (P5): ...when you are in a session... for counselling ... I can say that the important thing is the listening skills /okay/ you must listen /okay/ and then while you are listening you are trying to ... put things together $=/$ yes/ and separate other things.

In Extract 3, Lwando positioned herself as empathetic towards her client by "putting [her]self in her [client's] shoes". Listening empathetically and attentively provides the space for the client to share her story. This listening is not simply beneficial for the client, but is empowering for the counsellor who is now able to "understand what actually is happening"; to know, as Duvi says, how to respond and how to separate things important to the counselling from the things that are not.

Counsellors noted the importance of establishing trust; for example, by ensuring confidentiality. These ideas are taken up in the following two extracts.

\section{Extract 5:}

Amandisa (P4): There's ... [a lot] of trust mmm (with) the client ... is because there's a ... place to share our problem $/ \mathrm{mmm} /=$ and then your problem is stay there $/ y e s /$ there's no-one to listen [in on] your problem $/ \mathrm{mmm} /$ and ... (1) I ... not give anyone ... your details.

Extract 6:

Lwando (P3): it's very important that (.) the woman (.) understand $=/ \mathrm{mmm} /=$ why she (came to) you $=/$ yes $/=$ and trust $\underline{\text { you. }}$

In these extracts, Amandisa and Lwando suggest that creating a "place [of trust in which] to share [one's] problem" (Extract 5) is an important element of counselling and thus 
intervention. This is because trust and confidentiality are important aspects of effective intervention as they provide the safe space in which the client can share her stories.

\section{We Use Non-Directive Counselling}

The counsellors mentioned that they educate their clients about their rights and available intervention options. Within this micro-narrative, the participants saw the counsellor's job as being non-directive, simply assisting the client to make the best decision for her amongst the options presented, as exemplified in the extract below. However, this micro-narrative stands in contrast to the counsellors' stated orientation of working towards the client leaving the IPV relationship. Certain examples of subject positioning, however, show the slippage from nondirective to directive counselling.

\section{Extract 7:}

Amandisa (P4): ...women come to me to tell the story [and I am] (offering) counselling ... (educate) them about their rights /yes/ ... we are giving $i$-advice ... because I give $i$-option ...I don't say ... 'do these things' ... I give option ...(they have) to listen to take other ... option [they have to listen to learn about and choose an option].

\section{Extract 8:}

Shelly (P1): I always tell them (.) it's very good to talk $=/ \mathrm{mmm} /=$ not to keep inside you $\mathrm{mmm} /=$ talk about it so that $\ldots$ when you are talking $\ldots$ you're also getting the answers ... because the answer is not coming from people ... that you are sharing with (.) it's also coming with from you $=/ \mathrm{mmm} . / \ldots$ you started to do this by yourself $=/ \mathrm{mmm} /=$ you have to be strong for that.

In Extract 7, despite indicating that she does not say "do these things", Amandisa takes up the subject position of "educator" in relation to her clients, narrating how she informs them of their rights and the options open to them. In this way, she suggests that women are victims of ignorance: they are less knowledgeable than the counsellor or are un(der)educated and in need of information in order to best decide how to manage their IPV situation.

As the counsellors are speaking from an institutional space of helping women with IPV situations, they are considered qualified to speak about interventions because of their skills, expertise and knowledge in the field. Furthermore, being in an institutional 'space of helping' may reinforce counsellors' narrative of bondage/deliverance of which they see themselves as facilitators. They thus act as facilitators of deliverance by representing apparently neutral options to their clients. This might in turn obscure the contradiction between their stated neutrality and their practice of providing options that follow a restrictive narrative of successful counselling outcomes.

Nevertheless, these options are presented, according to Shelly, in a neutral way, with the client having to make her own decisions, as seen in Extract 8. In this extract, Shelly outlines that an element of counselling is women providing their own answers through talking with the counsellor. Shelly constructs her clients as having their own agency and responsibility for their futures. 
Interestingly, Amandisa initially indicates that she gives "advice". This is quickly corrected to giving "options" because telling clients what to do is viewed as problematic. Work undertaken to promote the perception of neutrality seems to be a defining feature of the first micro-narrative of 'good practice'. We will take up the slippage between non-directive and directive counselling in a later analytical section.

\section{When Things Go Well, We Feel Positive}

Counsellors spoke of positive experiences when reflecting on successful outcomes. Examples of these positive reflections can be seen in the following extracts:

\section{Extract 9:}

Shelly (P1): And ...you know you feel good when you are helping [others].

\section{Extract 10:}

Lwando (P3): Women ... they (.) becoming brave to report these cases that makes me very happy $=/ \mathrm{mmm} /=$ and even if the case has been taken to court and then the perpetrator is being sentenced $=/$ yes/= that makes me very happy.

Shelly's extract above expresses emotional satisfaction ("feel[ing] good") at essentially helping clients (to leave relationships characterised by IPV). Similarly, Lwando expresses happiness at women being 'brave' and reporting cases as well as the outcome of a perpetrator being sentenced in court. Importantly, Lwando's extract emphasises the view that successful interventions, as mentioned earlier, are those where the women leave relationships characterised by IPV. Clients are seen to change from the subject position of victim to survivor in the extracts as the women in these cases have been "brave": they have become survivors by taking the cases to court and having the perpetrator sentenced (Extract 10). It is in these circumstances that the counsellors experience positive emotions and feel that they are successful in their work of helping their clients.

\section{Counselling IPV Victims is Emotional Labour}

A clear micro-narrative that emerged in the interviews concerned the emotional labour that goes into providing counselling for IPV clients. Counsellors spoke about the sessions evoking strong emotions in them, the difficulty at times to remain objective as a result and thus the need to look after themselves. This can be seen in the extracts below:

\section{Extract 11:}

Shelly (P1): I got angry when ... (.) a woman is staying ... in an abusive relationship $/ \mathrm{mmm} /$ I got angry very angry $=/$ okay $/ \ldots$ because $\ldots$ I stayed (.) but I don't want someone to stay there because I know (.) how it's pain ... yho I know that

In Extract 11, Shelly's struggle to remain objective can be seen in her revealing that she felt angry when her clients chose not to leave relationships characterised by IPV. 
In constructing this micro-narrative, Shelly positioned herself as caring, as she is concerned for her clients and interested in their well-being. This can be seen in her remark that she understood and identified with the "pain" that the woman in this case was going through.

The anger Shelly felt at her client's inability to see the necessity of leaving the relationship links to work on wounded storytellers; Frank (2003, p. xv) suggests that anger or "chaos [is] in the claustrophobia of confronting others' inability to see what [one] so clearly feel[s]". Shelly, as the wounded healer, managed, eventually, to accomplish the situation most desired by the counsellors - that women leave abusive relationships. As such, she feels compelled to assist the client along the same path, and thus experiences the countertransference of anger when this does not occur. While confessing to anger, Shelly also positioned herself as knowledgeable (through the experience of not leaving at first). In this way, the woman client is positioned as a victim with little agency.

As a result of their work being emotionally taxing, the counsellors spoke about trying to look after themselves and one another in order to continually carry out their work effectively, as can be seen in the following extracts:

\section{Extract 12:}

Nomsa (P2): We still have the [weekly] supervision ... so each week we bring ... all those worrying cases $/ \mathrm{mmm} /$ and also we ... get ... advices from the:: other ... colleagues /okay/ ... we ... present your [our] case [P claps] and all other ... colleagues will intervene in your case $/$ that's great $/=[\mathrm{we}]$ discuss discuss discuss (.).

\section{Extract 13:}

Amanda (P7): I have in the past (.) organised ... (.) consultations with:: ... a private person or someone $=/ \mathrm{mmm}:: /=\ldots$ to deal with that $=/ \mathrm{yes} /=\ldots$ to make sure that it doesn't overwhelm [me].

Nomsa indicates that she and her colleagues were interested in supporting one another and were concerned about one another's wellbeing in light of the emotionally taxing work that they do. They discuss "all those worrying cases", providing input and advice. Nomsa alluded to the idea that the helper needs help to navigate the "worry", and suggested that the counsellors take on the burden of their clients' IPV experiences by feeling empathy for the clients. Amanda expressed concern over the real possibility of the work overwhelming her emotionally, and pointed, therefore, to the need to consult a person outside of the NGO for professional supervision.

\section{We Provide Moral Guidance and Suggestions}

As was noted earlier, the counsellors indicated that they provide non-directive counselling, in particular presenting their clients with options for resolving the problems they are facing. However, the counsellors also spoke at times about encouraging their clients to engage in certain practices/behaviours through providing moral guidance or suggestions. This occurred mostly when discussing matters involving pregnancy or children. 
These moral suggestions included encouraging women to look after themselves during pregnancy and to consider the children: not to leave them behind if the woman was thinking of leaving a relationship characterised by IPV. This stance is opposed to letting the woman freely choose their options without such suggestions. In relation to this, it is important to note that the moral suggestions and guidance offered by the counsellors were largely influenced by culturallylocated and socially-sanctioned constructions of gendered roles and subjectivities, especially those around the concept of motherhood. These ideas can be noted in the extracts below:

\section{Extract 14:}

Mrs. X (P8): I always remind them that it's only temporary that your tummy is big. You're going to have your baby in your arms no more in your:: tummy after nine months so for the nine months that the baby is depending on you for survival you need to take better care of yourself .

\section{Extract 15:}

Shelly (P1): what are you going to do? /yes/ (.) becau::se (2) if you ... go home /(1) yes/ it can be (a problem) $/ \mathrm{mmm} /$... if you think to go [if you are thinking of leaving the relationship chraracterised by IPV] you must think about your children=/yes/ if (you feel you) (2) go out from that door $=/ \mathrm{mmm} /$ (.) to me:: (.) it's better to put your children in front (.) not to leave the ... children behind'.

Mrs. X (participant's chosen pseudonym) is attempting to reassure her client that the pregnancy is temporary and that her client must "take better care of [her]self". In this way, Mrs. X was positioning the woman as a nurturer with a responsibility towards her children. While not problematic in and of itself, this positioning leads to the moral injunction of self-care. In providing this moral injunction, Mrs. X was subtly implying that failure to attend to this self-care could result in damage to the children. Preventing damage to the children thus becomes the sole responsibility of the woman; failure to engage in self-care results in the woman being positioned as wilfully refusing to prevent damage. Shelly stated that if a woman was thinking of leaving a relationship characterised by IPV, she "must think about [her] children". As with Mrs. X, Shelly was placing herself in a superior subject position as she seemed to feel that she had the status, knowledge and expertise in order to provide this moral guidance.

\section{Discussion}

The micro-narratives the counsellors related of their experiences of counselling women in IPV relationships, and the associated subject positions, point to a number of conundrums or double binds. The counsellors positioned themselves as professionals who implement good counselling practices (praise, listening, confidentiality, trust); at the same time, they could not help but feel angry, burnt-out and overwhelmed. When counselling was successful, the counsellors felt positive, but there were often failures, which they reported led to anger. This anger could be viewed as the countertransference of wounded healers, who, having suffered similar abuses, 
simultaneously empathise with the client, feel righteous anger towards the perpetrator, and dismay at the lack of 'success' (Zerubavel and Wright 2012).

Throughout the data, 'success' was described by the counsellors as the woman removing herself from the IPV relationship. As such, the classic narrative of women being delivered from bondage formed the foundation of counselling. Within this narrative, women who remain are regarded as victims and women who leave are considered survivors. This creates a dichotomy or an 'all-or-nothing' position within the counselling dynamic. The counsellor's emotional investment in the client and relationship building (such as ensuring confidentiality and thus building trust, listening attentively, displaying empathy where possible, promoting strength) was seen as worthwhile when the woman leaves the relationship (see also Lewis et al. 2005). However, the counsellors indicated becoming discouraged when the woman remained within the relationship.

Counsellors indicated that they used non-directive counselling, informing women of their rights and options and assisting them in making decisions. In this, however, the counsellors positioned themselves as experts on the options open to women, and regarded the women as experts on their own lives. However, there were limits displayed to simply allowing women to make their own decisions. When it came to matters to do with pregnancy or children, the counsellors felt it imperative to provide moral guidance on the correct form of action; i.e., that women must engage in self-care and take their children with them if they were to leave the relationship characterised by IPV.

The fact that these counsellors invested in a narrative of female survivorhood, that implied leaving violent intimate relationships, is perhaps not surprising, given the high rates of abuse in the country and that all counsellors interviewed were women. Counsellors who have experienced abuse themselves (some voluntarily revealed this in the interviews, as can be seen in one or two extracts here) may create an emotional weight or responsibility if their female clients choose not to leave the relationship.

We argue that the conundrums evident in the counsellors' talk stem from the fact that they counsel the women within already entrenched patriarchal and structural power relations. There is no guarantee that the women will be able to successfully leave their current relationship characterised by IPV, or avoid another one in the future, and the counsellors were painfully aware of this. They nevertheless held onto the narrative of "bondage to deliverance" or "victimhood to survivorhood" as the only valid outcome of counselling. This singular narrative regarding what constitutes a 'successful' outcome of counselling women who have had experiences of IPV during pregnancy, does not take into account the sometimes very real structural and/or cultural obstacles that frequently prevent women from leaving relationships characterised by IPV (e.g., economic dependency on their partners for survival, or culturally-located customs and traditional practices regarding marriage bonds) (see Fleischack et al. 2017). This 'narrow' view of counselling outcomes may, therefore, be more likely to fail than not. Indeed counsellors' insistence on clients' adherence to patriarchal and culturally-entrenched forms of motherhood may unwittingly constitute a barrier to successfully leaving an IPV relationship, thereby undermining their own criterion for a successful outcome (that is, leaving the IPV relationship).

The counsellors indicated that they felt overwhelmed, fatigued and disappointed if their clients did not leave the IPV relationship. This emotional cost suggests that the counsellors as well as the clients were victims, working against a patriarchal system. In this tough and challenging environment, the counsellors often turned to one another for help, support and guidance. 


\section{Implications of the Findings for Counselling and Training}

Our research illustrates the importance of studying not only clients' but also counsellors' experiences so as to improve counselling concerning IPV. The conundrums illustrated above point to a number of implications in terms of the counselling process. Firstly, to obviate counsellors feeling that their emotional investment has not been worthwhile, a useful perspective would be to see clients as complex beings: somewhere between victim and survivor, slipping between the two depending on circumstances, or as neither. This may also allow the counsellors to see and value small gains in their counselling process. Examples include: when the women come to counselling in the first place, because they feel hopeful that they can receive some assistance; valuing women having a comfortable space to share their stories to gain some insight (which also links to Moon's 2006 idea that story telling is a means to healing); and the notion of women engaging in everyday practices that serve to increase their agency and reduce the IPV, even if it involves remaining in the relationship.

Thus, secondly, the narrative of bondage and delivery (i.e., being in an IPV relationship followed by leaving) needs to be nuanced to allow for other narratives of success, including changing dynamics within the household or simple mechanisms to reduce the possibility of abuse. This is particularly important in circumstances where, as mentioned earlier, some women feel unable, for a range of reasons (e.g., financial, childcare), to leave the relationship. Research into IPV risk factors and reduction interventions have highlighted key risks and aspects that, if addressed, might lower the likelihood of IPV occurring. These include addressing, for example, poor relationship communication and conflict management skills (Abrahams et al. 2006; Hatcher et al. 2014), as well as economic and social empowerment initiatives (Jewkes et al. 2014; Kim et al. 2007; Pronyk et al. 2006). These all aim to alter and/ or develop troubling dynamics within relationships to reduce IPV, rather than arguing that women should simply leave situations of IPV.

Thirdly, recognising that counsellors and clients are both steeped in patriarchal power relations that, in the first place, foster IPV and, in the second place, make resolving the situation very difficult is important. The kind of support received from colleagues that was spoken about by participants is essential. Peer support as well as sensitive clinical supervision go a long way in developing growth and self-care in counsellors, as identified by Friesema (2016). Equally, though, counselling needs to be supplemented with a focus on accountability or collective responsibility for IPV in communities. This, thus, suggests the need for widerscale interventions and advocacy. Running these kinds of interventions alongside counselling may assist counsellors in feeling less burnt-out and despondent about what is and is not achievable in this context.

Finally, the conundrums evidenced in the 'wounded healer' position need to be taken up in training and clinical supervision. As noted above and in the literature (Zerubavel and Wright 2012), 'wounded healers' have the potential to empathise with clients and to de-stigmatise being the victim of abuse. On the flip side, uncontained emotions such as anger may surface and may interfere with the sessions. This is particularly pertinent when, as in this case, the 'success' of the counselling is narrowly defined. Training and supervision, thus, could concentrate on: (1) allowing the counsellors to reflect on and work through countertransference emotions, and (2) ensuring that the client's options and choices are taken seriously and supported without the implication that counsellor-led outcomes are better. 


\section{Compliance with Ethical Standards}

Conflict of Interest The authors declare that they have no conflict of interest.

\section{Appendix}

Ian Parker's (1992) transcription conventions (Adapted)

\begin{tabular}{|c|c|}
\hline Symbol & Meaning \\
\hline Round brackets ( ) & Indicates doubts arising about the accuracy of material \\
\hline Ellipses ... & To show when material is omitted from the transcript \\
\hline Square brackets [ ] & To clarify something for the reader \\
\hline Forward slashes / / & Indicates noises, words of assents and others \\
\hline Equals sign $=$ & $\begin{array}{l}\text { Indicates the absence of a gap between one speaker and another at } \\
\text { the end of one utterance and the beginning of the next utterance }\end{array}$ \\
\hline $\begin{array}{l}\text { Round brackets with number } \\
\text { inserted, e.g. ( } 2 \text { ) }\end{array}$ & Indicates pauses in speech with the number of seconds in round brackets \\
\hline Round brackets with full stop (.) & Indicates pauses in speech that last less than a second \\
\hline Colon :: & Indicates an extended sound in the speech \\
\hline Underlining & Indicates emphasis in speech \\
\hline Single inverted commas " & $\begin{array}{l}\text { Indicates words or phrases which have been quoted; either the counsellor } \\
\text { quoting themselves or quoting their clients, in this research }\end{array}$ \\
\hline
\end{tabular}

\section{References}

Abrahams, N., Jewkes, R., Laubscher, R., \& Hoffman, M. (2006). Intimate partner violence: Prevalence and risk factors for men in Cape Town, South Africa. Violence and Victims, 21(2), 247-264.

Blommaert, J. (2006). Applied ethnopoetics. Narrative Enquiry, 16(1), 181-190.

Britton, H. (2006). Organising against gender violence in South Africa. Journal of Southern African Studies, $32(1), 145-163$.

Fleischack, A., Macleod, C., \& Bohmke, W. (2017). "The man can use that power", "she got courage" and "inimba": Discursive resources in counsellors' talk of intimate partner violence: Implications for practice. Social Work/Maatskaplike Werk, 53(1), 127-144.

Fok, S. (2011). Micro-narratives in contemporary Chinese art: A case study of Cao Fei's Pearl River Delta antiheroes. Asian Studies Review, 35, 499-520.

Frank, A. W. (2003). The wounded storyteller: Body, illness and ethics. Chicago: The University of Chicago Press.

Friesema, A. (2016). Domestic violence counselors' supervision experiences: A qualitative inquiry. (unpublished doctoral thesis). Northern Illinois University, USA.

Gupta, J., Silverman, J. G., Hemenway, D., Acevedo-Garçia, D., Stein, D. J., \& Williams, D. R. (2008). Physical violence among intimate partners and related exposures to violence among South African men. Canadian Medical Association Journal, 179(6), 535-541.

Haaken, J. (2010). Hard knocks: Domestic violence and the psychology of storytelling. East Sussex: Routledge.

Hatcher, A. M., Romito, P., Odero, M., Bukusi, E. A., Onono, M., \& Turan, J. M. (2013). Social context and drivers of intimate partner violence in rural Kenya: Implications for the health of pregnant women. Culture, Health \& Sexuality: An International Journal for Research, Intervention and Care, (15)4, 404419.

Hatcher, A., Colvin, C. J., Ndlovu, N., \& Dworkin, S. L. (2014). Intimate partner violence among rural South African men: Alcohol use, sexual decision-making, and partner communication. Culture, Health \& Sexuality, 16(9), 1023-1039.

Hiles, D., \& Čermák, I. (2008). Narrative psychology. In C. Willig \& W. Stainton-Rogers (Eds.), The Sage handbook of qualitative research in psychology (pp. 147-164). London: Sage Publications Ltd.

Iliffe, G., \& Steed, L. G. (2000). Exploring the counselor's experience of working with perpetrators and survivors of domestic violence. Journal of Interpersonal Violence, 15(4), 393-412.

Iverson, K. M., Stirman, S. W., Street, A. E., Gerber, M. R., Carpenter, S. L., Dichter, M. E., Bair-Merritt, M., \& Vogt, D. (2016). Female veterans' preferences for counseling related to intimate partner violence: Informing patient-centered interventions. General Hospital Psychiatry, 40, 33-38. 
Jewkes, R., Levin, J., \& Penn-Kekana, L. (2002). Risk factors for domestic violence: Findings from a South African cross-sectional study. Social Science \& Medicine, 55(9), 1603-1617.

Jewkes, R., Gibbs, A., jama-Shai, N., Willan, S., Misselhorn, A., Mushinga, M., Washington, L., Mbatha, N., \& Sikweyiya, Y. (2014). Stepping stones and creating futures intervention: Shortened interrupted time series evaluation of a behavioural and structural health promotion and violence prevention intervention for young people in informal settlements in Durban, South Africa. BMC Public Health, 14, 1325.

Jovchelovitch, S., \& Bauer, M. W. (2000). Narrative interviewing. In M. W. Bauer \& G. Gaskell (Eds.), Qualitative researching with text, image and sound: A practical handbook (pp. 57-74). London: SAGE.

Joyner, K., \& Mash, R. J. (2011). The value of intervening for intimate partner violence in South African primary care: Project evaluation. BMJ Open, 1, 1-9.

Joyner, K., \& Mash, R. J. (2012). A comprehensive model for intimate partner violence in South African primary care: Action research. BMC Health Services Research, 12, 399-408.

Kaldine, F. (2007). Violence against women and children. In M. Visser (Ed.), Contextualising community psychology in South Africa (pp. 229-242). Pretoria: Van Schaik Publishers.

Kim, J., \& Motsei, M. (2002). "Women enjoy punishment": Attitudes and experiences of gender-based violence among PHC nurses in rural South Africa. Social Science \& Medicine, 54, 1243-1254.

Kim, J. C., Watts, C. H., Hargeaves, J. R., Ndhlovu, L. X., Phetla, G., Morison, L. A., Busza, J., Porter, J. D. H., \& Pronyk, P. (2007). Understanding the impact of a microfinance-based intervention on women's empowerment and the reduction of intimate partner violence in South Africa. American Journal of Public Health, 97(10), 1794-1802.

Lewis, M. J., West, B., Bautista, L., Greenberg, A. M., \& Done-Perez, I. (2005). Perceptions of service providers and community members on intimate partner violence within a Latino community. Health, Education \& Behaviour, 32(1), 69-83.

Mash, R. J., Fairall, L., Adejayan, O., Ikpefan, O., Kumari, J., Mathee, S., Okun, R., \& Yogolelo, W. (2012). A morbidity survey of South African primary care. PLoS One, 7(3), 1-12.

Mbokota, M., \& Moodley, J. (2004). Domestic violence - An antenatal survey at king Edward VIII hospital, Durban. South African Journal of Obstetrics and Gynaecology, 10(2), 46-48.

McHattie, L. J. (2011). What helps, what hinders when counselling women who have experienced intimate partner violence (Master's thesis). Simon Fraser University, Burnaby.

Miller, T. W., Veltkamp, L. J., Lane, T., Bilyeu, J., \& Elzie, N. (2002). Care pathway guidelines for assessment and counseling for domestic violence. The Family Journal, 10(1), 41-48.

Modiba, L. M., Baliki, O., Mmalasa, R., Reineke, P., \& Nsiki, C. (2011). Pilot survey of domestic abuse amongst pregnant women attending an antenatal clinic in a public hospital in Gauteng Province in South Africa. Midwifery, 27(6), 872-879.

Moon, C. (2006). Narrating political reconciliation: Truth and reconciliation in South Africa. Social \& Legal Studies, 15(2), 257-275.

Mwau, A. (2000). Counselling victims of domestic violence in Kenya. In M. Turshen (Ed.), African women's health. Eritrea: Africa World Press.

Njuho, P. M., \& Davids, A. (2012). Patterns of physical assaults and the state of healthcare systems in South African communities: Findings from a 2008 population-based national survey. South Africa Journal of Psychology, 42(2), 270-281.

Ntaganira, J., Muula, A. S., Masaisa, F., Dusabeyezu, F., Siziya, S., \& Rudatsikira, E. (2008). Intimate partner violence among pregnant women in Rwanda. BMC Women's Health, 17(8), 1-7.

O’Donovan, D. (2006). Moving away from "failing boys" and "passive girls": Gender meta-narratives in gender equity policies for Australian schools and why micro-narratives provide a better policy model. Discourse: Studies in the Cultural Politics of Education, 27(4), 475-494.

Oswald, R. F., Fonseca, C. A., \& Hardesty, J. L. (2010). Lesbian mothers' counseling experiences in the context of intimate partner violence. Psychology of Women Quarterly, 34(3), 286-296.

Parker, I. (1992). Discourse dynamics: Critical analysis for social and individual psychology. London: Routledge.

Pronyk, P. M., Hargreaves, J. R., Kim, J. C., Morison, L. A., Phetla, G., Watts, C., Busza, J., \& Porter, J. D. H. (2006). Effect of a structural intervention for the prevention of intimate-partner violence and HIV in rural South Africa: A cluster randomised trial. The Lancet, 368, 1973-1983.

Rasool Bassadien, S., \& Hochfeld, T. (2005). Across the public/private boundary: Contextualising domestic violence in South Africa. Agenda: Empowering Women for Gender Equity, 19(66), 4-15.

Rhodes, N. R., \& McKenzie, E. B. (1998). Why do battered women stay?: Three decades of research. Aggression and Violent Behaviour, 3(4), 391-406.

Roddy, J. K. (2013). Client perspectives: The therapeutic challenge of domestic violence counselling - A pilot study. Counselling and Psychotherapy Research, 13(1), 53-60.

Roddy, J. (2016). Counselling and psychotherapy after domestic violence: A client view of what helps recovery. Cham: Springer. 
Roddy, J. K., \& Gabriel, L. (2019, in press). A competency framework for domestic violence counselling. British Journal of Guidance \& Counselling.

Seedat, S., Stein, D. J., Jackson, P. B., Heeringa, S. G., Williams, D. R., \& Myer, L. (2009). Life stress and mental disorders in the South African stress and health study. South African Medical Journal, 99(5), 375-382.

Silverman, J. G., Raj, A., \& Clements, K. (2004). Dating violence and associated sexual risk and pregnancy among adolescent girls in the United States. Pediatrics, 114(2), 220-225.

Taylor, S., \& Littleton, K. (2006). Biographies in talk: A narrative-discursive research approach. Qualitative Sociology Review, (2)1), 22-38.

Vogelman, L., \& Eagle, G. (1991). Overcoming endemic violence against women in South Africa. Social Justice, $18(1 / 2), 209-229$.

Watts, C., \& Mayhew, S. (2004). Reproductive health services and intimate partner violence: Shaping a pragmatic response in sub-Saharan Africa. International Family Planning Perspectives, 4(30), 207-213.

Wengraf, T. (2001). Qualitative research interviewing. London: Sage Publications Ltd.

Wood, K., Lambert, H., \& Jewkes, R. (2007). "Showing roughness in a beautiful way": Talk about love, coercion, and rape in South African youth sexual culture. Medical Anthropology Quarterly, 21(3), 277-300.

Wood, K., Lambert, H., \& Jewkes, R. (2008). "Injuries are beyond love": Physical violence in young South Africans' sexual relationships. Medical Anthropology, 27(1), 43-69.

Young, R. A., \& Collin, A. (2004). Introduction: Constructivism and social constructionism in the career field. Journal of Vocational Behavior, 64(3), 373-388.

Zerubavel, N., \& Wright, M. O. D. (2012). The dilemma of the wounded healer. Psychotherapy, 49(4), $482-491$.

Zust, B. L., Housley, J., \& Klatke, A. (2017). Evangelical Christian pastors' lived experience of counseling victims/survivors of domestic violence. Pastoral Psychology, 66(5), 675-687.

Publisher's Note Springer Nature remains neutral with regard to jurisdictional claims in published maps and institutional affiliations. 